\title{
A fuzzy logic-based automation toward intelligent air conditioning
} systems

\author{
Gunawan Dewantoro*1, Benedictus Edwin Nugraha ${ }^{2}$, Fransiscus Dalu Setiaji ${ }^{3}$ \\ Department of Electronic and Computer Engineering, Satya Wacana Christian University, Indonesia ${ }^{1,2,3}$
}

\section{Article Info}

Keywords:

Automation, Fuzzy Logic, Air Conditioner,

Efficiency, Remote Control

\section{Article history:}

Received 21 October 2020

Accepted 18 November 2020

Published 30 November 2020

\section{Cite:}

Dewantoro, G., Nugraha, B., \& Setiaji, F. (2020). A Fuzzy Logic-Based Automation toward Intelligent Air Conditioning Systems. Kinetik: Game Technology, Information System, Computer Network, Computing, Electronics, and Control, 5(4).

doi:https://doi.org/10.22219/kinetik.v5i4.1135

${ }^{*}$ Corresponding author.

Gunawan Dewantoro

E-mail address:

gunawan.dewantoro@staff.uksw.edu

\begin{abstract}
Most of the energy used in residential buildings originates from air conditioners. Meanwhile, air conditioner manufacturers are addressing this issue by the production of efficient air conditioners. However, the convertible frequency air conditioners are expensive, up to $60 \%$ higher than the fixed frequency control air conditioners. Besides the human behavior in determining the temperature, setpoint plays an important role regardless of the air conditioners technology used. This study incorporated intelligence in setting up the temperature by means of specially designed remote control. The Tsukamoto fuzzy reasoning was utilized as a decision making system with two inputs, namely the outdoor temperature and the number of occupants. The device used DHT22 as the temperature sensor and $\mathrm{HC}$-SR04 to detect incoming and outgoing occupants. Furthermore, the fuzzy inference system generated infrared signal associated with the temperature setpoint. This signal was received by the air conditioner receiver to adjust the temperature setpoint accordingly. The result of this study showed that the fuzzy inference system determines the temperature setpoint appropriately under variations of surrounding temperature and the number of occupants. The proposed approach yielded a satisfactory perception of thermal comfort and also a promising approach to energy conservation.
\end{abstract}

\section{Introduction}

The need for heating, ventilation, and air conditioning (HVAC) systems have now become very important as the demand for thermal comfort rises. The rapid escalation of energy consumption of HVAC systems draws concerns since it is now the major energy usage in office, residential, and non-residential buildings for many countries. HVAC systems account for almost $50 \%$ of the energy utilized in buildings, and about $20 \%$ of total energy usage in developed countries [1]. The demand for energy for buildings worldwide is at $40 \%$ and will shortly reach $60 \%$ according to the statistics [2], of which $48 \%$ of the comfort parameters were thermal or HVAC [3].

Previous studies have been attempted to address thermal energy management in residential buildings. A simulation was built which represents a smart home containing the air conditioner and a sensor network, in which a gateway node connected both sides [4]. Another smart home for a temperature system was established using Android applications together with microcontrollers [5]. Decision support and energy management systems were employed in existing houses to reduce energy consumptions. The control logic was comprised of six available logics, namely: comfort, economy, emergency, energy, power, and thermal storage. However, the rational utilization of electric appliances still manually relied on inhabitant [6]. A cyber-physical system of home temperature control was built to actuate air conditioner and/or openings by means of a Proportional-Integral-Derivative (PID) controller and the so-called hybrid controller [7]. A Matlab/Simulink based simulation verified the effectiveness of the proposed method to reach the desired temperatures. The use of smart sensors was also introduced. Smartphones, temperature sensors, bracelet-like device, and human motion sensors were integrated to establish intelligent air-conditioning systems [8]. The wearable devices were used to determine the sleeping state of the occupants which then could reduce the energy consumptions.

Several studies have also incorporated intelligent controls to HVAC systems. A hybrid of neural network and fuzzy system were used to regulate blower, air conditioner, and recirculation gates to provide comfortable temperature with less energy [9]. The adaptive properties were obtained via a hybrid learning method based on the gradient descent and least square error estimate. Fuzzy logic systems have also been occupied as intelligent controllers by controlling the compressor duty cycle [10]. In [11], five fuzzy inputs were selected to determine four fuzzy output variables. Fuzzy rule base was constructed using Fuzzy Logic Toolbox in Matlab. However, there was a lack of experiments to verify the simulations. The use of fuzzy sets was also shown in [12] to predict retail prices as well as outdoor temperatures to set the next 24-hour indoor temperatures. Nevertheless, the forecasting stages were prone to uncertainties. Besides, the next 24-hour indoor temperatures were set in a fixed manner, making it not adaptable to sudden changes, e.g. the number of occupants. Another approach to forecasting the power consumption of air conditioners was shown in [13] which employed a neural network combined with an autoregressive model.

Cite: Dewantoro, G., Nugraha, B., \& Setiaji, F. (2020). A Fuzzy Logic-Based Automation toward Intelligent Air Conditioning Systems. Kinetik: Game Technology, Information System, Computer Network, Computing, Electronics, and Control, 5(4). doi:https://doi.org/10.22219/kinetik.v5i4.1135 
The works mentioned above addressed how a control strategy ensures that the room temperature tracks a given static or varying setpoint. However, the setpoint itself is determined by humans and it may lead to either lack of thermal comfort or energy waste. The mean energy consumption saving corresponding to a $1 \mathrm{oC}$ increase of setpoint is around $6.14 \%$ [14]. Without sacrificing thermal comfort levels, by increasing the setpoint of $22.2^{\circ} \mathrm{C}\left(72{ }^{\circ} \mathrm{F}\right)$ to $25^{\circ} \mathrm{C}\left(77^{\circ} \mathrm{F}\right)$, an average of $27 \%$ total HVAC energy savings were attained [15]. Also, various health problems might arise from improper indoor temperature settings [16][17]. Determining the indoor temperatures using air conditioners have been subjective from one person to another [18]. Occupancy load as well as inhabitants' behavior inside rooms have been shown to have great influences on space heating which led to the increase of ventilation demand, HVAC energy consumption, and building controls [19]. The thermal profile of buildings due to climate and the number of occupants for energy management and comfort control has been investigated [20][21]. In addition, the thermal comfort perception might vary for each occupant with respect to socio-economic contexts, housing locations, and physiological thermal satisfaction [22][23][24][25].

Considering the concerns, this paper attempted to develop an intelligent-based control to set the indoor temperatures with respect to outdoor temperatures and occupants with a fuzzy reasoning embedded microcontroller as the decision-making system. This approach, to the best of our knowledge, has never been conducted elsewhere and is of significance to this paper. The effectiveness of this approach was measured based on the perceived thermal comfort and compressor output.

\section{Research Method}

\subsection{Design of Fuzzy-Based Inference Systems}

The first stage of fuzzy inference system is the determination of the input - output and their membership functions. Each membership function is associated with a specific linguistic value. This study employed two inputs, namely outdoor temperature and the number of occupants. To determine the universe of discourse for the outdoor temperature, preliminary data were recorded during June 2019 which is considered to be the time when the average annual temperature takes place [26], as shown in Figure 1.

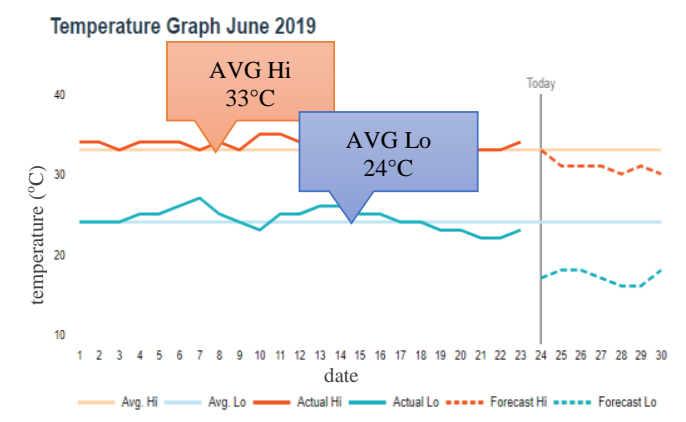

Figure 1. Average, Maximum, and Minimum of Temperature

Having these temperature data, membership function of the outdoor temperature could be designed, shown in Figure 2. The variable $x$ denotes the universe of discourse and $\mu$ denotes the membership degree.

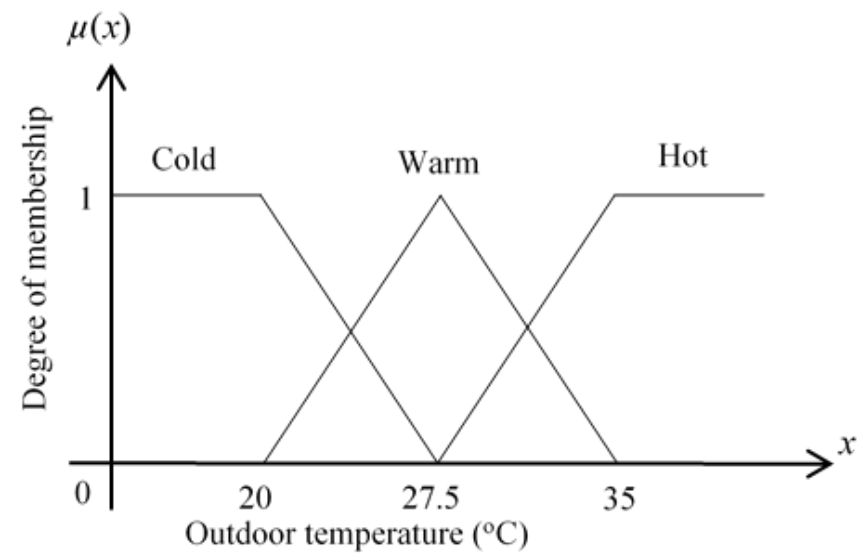

Figure 2. Membership Functions of Outdoor Temperature

(c) 2020 The Authors. Published by Universitas Muhammadiyah Malang

This is an open access article under the CC BY SA license. (https://creativecommons.org/licenses/by-sa/4.0/) 
Based on the above membership functions, the fuzzification stage was conducted by using Equation 1, Equation 2, and Equation 3.

$$
\begin{aligned}
& \mu(x)=\left\{\begin{array}{cc}
\frac{27.5-x}{7.5} & , 20 \leq x \leq 27.5 \\
0 & , x>27.5
\end{array}\right. \\
& \mu(x)=\left\{\begin{array}{cc}
\frac{x-20}{7.5} & , x<20 \text { or } x>35 \\
\frac{35-x}{7.5} & , 20 \leq x<27.5
\end{array}\right. \\
& \mu(x)=\left\{\begin{array}{cc}
\frac{x-27.5}{7.5} & , 27.5 \leq x \leq 35 \\
1 & , x \geq 35
\end{array}\right.
\end{aligned}
$$

Equation 1, Equation 2, and Equation 3 determine the degree of membership of each fuzzy set named Cold, Warm, and Hot, respectively. Meanwhile, the universe of discourse for occupants was defined according to the room capacity, i.e. 50 persons. Therefore, the membership function of occupants is depicted in Figure 3.

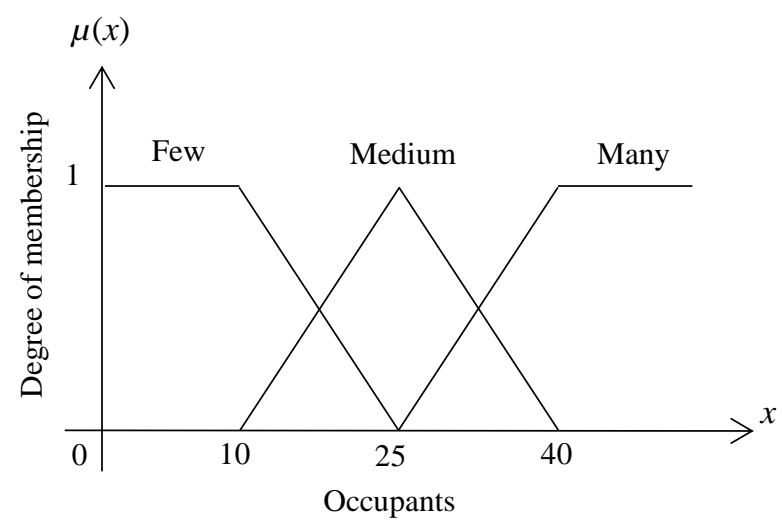

Figure 3. Membership Functions of Occupants

The conversion to fuzzy variables for the above membership functions was formulated by Equation 4, Equation 5, and Equation 6.

$$
\begin{aligned}
& \mu(x)=\left\{\begin{array}{cc}
1 & , x<10 \\
\frac{25-x}{15} & , 10 \leq x \leq 25 \\
0 & , x>25
\end{array}\right. \\
& \mu(x)=\left\{\begin{array}{cc}
0 & , x<10 \text { or } x>40 \\
\frac{x-10}{15} & , 10 \leq x<25 \\
\frac{40-x}{15} & , 25 \leq x \leq 40
\end{array}\right. \\
& \mu(x)=\left\{\begin{array}{cc}
0 & , x \leq 25 \\
\frac{x-25}{15} & , 25 \leq x \leq 40 \\
1 & , x \geq 40
\end{array}\right.
\end{aligned}
$$


Equation 4, Equation 5, and Equation 6 determine the degree of membership of each fuzzy set named Few, Medium, and Many, respectively. Those fuzzy variables were then processed using if-then rules as formulated in Table 1. The rule base table was formulated according to common understanding where highly-occupied room or hot surroundings will make the indoor temperature increase. On the contrary, few occupants in a room or cold environments will lead to low indoor temperature. For each condition, the setpoint was determined such that all occupants experience thermal comfort.

Table 1. Rule Base Table

\begin{tabular}{ccccc}
\hline \multirow{2}{*}{ Setpoint } & \multicolumn{3}{c}{ Outdoor Temperature $\left({ }^{\circ} \mathrm{C}\right)$} \\
\cline { 2 - 5 } & Few & Cold & Warm & Hot \\
\hline \multirow{3}{*}{ Occupants } & High & High & Middle \\
& Medium & High & Middle & Low \\
& Many & Middle & Low & Low \\
\hline
\end{tabular}

Last, the defuzzification stage converted the fuzzy variables back to the crisp variable, i.e. setpoint. The membership function for the setpoint is shown in Figure 4. This configuration is initially based on the recommendation from the Occupational, Health, and Safety Centers where the temperature is set roughly in the range $21^{\circ} \mathrm{C}-23^{\circ} \mathrm{C}$ [4].

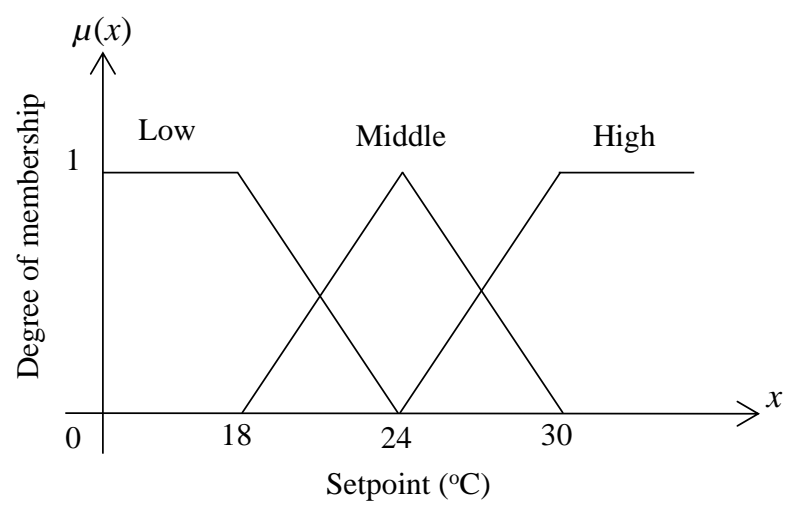

Figure 4. Membership Functions of Setpoint

The conversion from fuzzy variables back to the crisp variable was formulated by Equation 7, Equation 8, and Equation 9 for fuzzy set Low, Middle, and High, respectively.

$$
\begin{aligned}
& \mu(x)=\left\{\begin{array}{cc}
1 & , x<18 \\
\frac{24-x}{6} & , 18 \leq x \leq 24 \\
0 & , x>24
\end{array}\right. \\
& \mu(x)=\left\{\begin{array}{cc}
0 & , x<18 \text { or } x>30 \\
\frac{x-18}{6} & , 18 \leq x<24 \\
\frac{30-x}{6} & , 24 \leq x \leq 30
\end{array}\right. \\
& \mu(x)=\left\{\begin{array}{cc}
0 & , x \leq 24 \\
\frac{x-24}{6} & , 24 \leq x \leq 30 \\
1 & , x \geq 30
\end{array}\right.
\end{aligned}
$$

The air conditioner setpoint was then obtained by the weighted average method and transmitted in the form of infrared signal.

\subsection{Experiment Setup}

Figure 5 shows the installation of the hardware device:

(C) 2020 The Authors. Published by Universitas Muhammadiyah Malang

This is an open access article under the CC BY SA license. (https://creativecommons.org/licenses/by-sa/4.0/) 


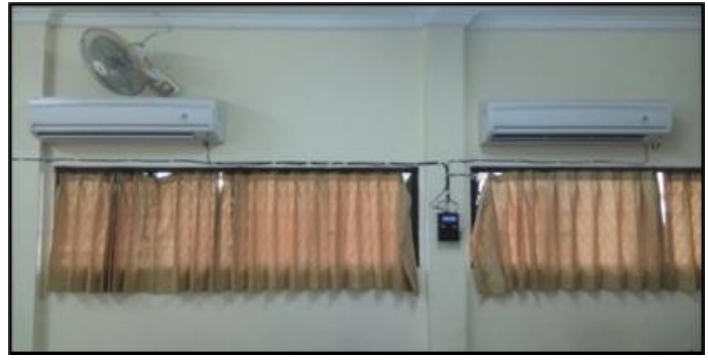

(a)

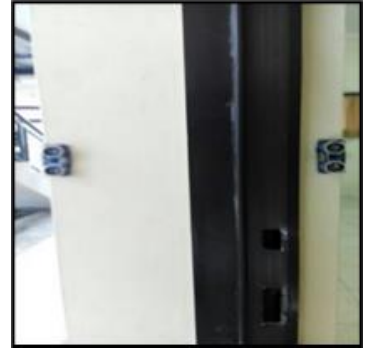

(b)

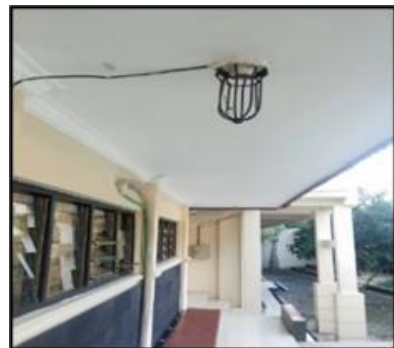

(c)

Figure 5. Hardware Installation: (a) Indoor, (b) Ultrasonic Sensors, and (c) Temperature Sensor

The hardware system consisted of various parts as depicted in Figure 6.

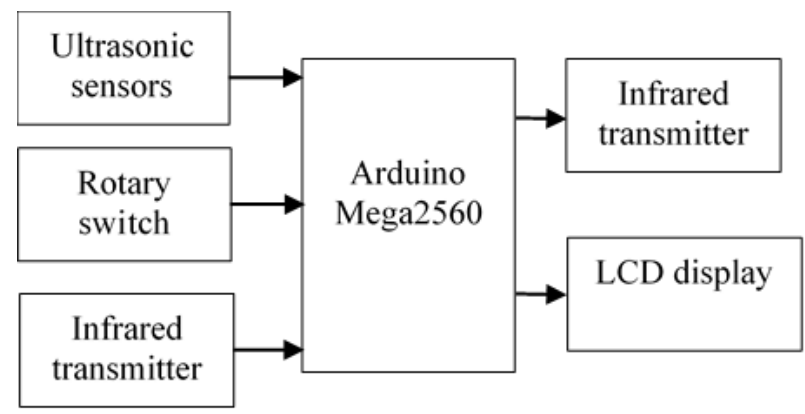

Figure 6. Air Conditioner Control Diagram Blocks

The realization of this controller is in the form of a compact panel box as shown in Figure 7. This system employed a 9 Volts power supply to power all devices. Arduino Mega2560 was used as a microcontroller to infer the fuzzy reasoning. In the decision-making process, two inputs were taken into consideration, namely the outdoor temperature and the number of occupants. To acquire these data, two ultrasonic sensors HC-SR04 detected the number of incoming and outgoing occupants automatically. Meanwhile, DHT22 was used as the outdoor temperature sensor. The control box was also equipped with a rotary switch to set the menu displayed on the Liquid Crystal Display (LCD) screen. The fuzzy inference system- generated information is associated with the air conditioner temperature setpoint. Then, the infrared transmitter would send an infrared signal toward the air conditioner. The transmitted infrared signal represented the temperature setpoint whose format was in accordance with the occupied air conditioner brand, e.g. Daikin. Each input and output information was displayed on the LCD screen. The flowchart of the algorithm is shown in Figure 8.

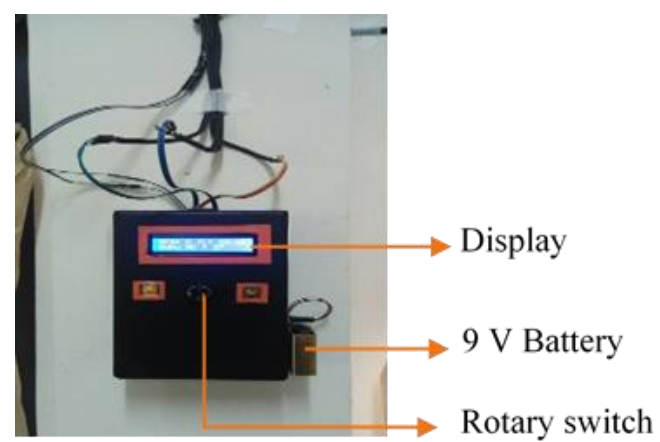

Figure 7. Control Panel Box

This device was activated and deactivated by an on/off button on the panel box. A DHT22 temperature sensor mounted on the outside wall would acquire the outdoor temperature. Two ultrasonic sensors were mounted aside of the doorway, one on the inner side and the other one on the outer side. If the outer sensor and inner sensor detected passing object consecutively, then the number of occupants was increased by one. Conversely, if the inner sensor detected first and followed by the outer sensor, then the number of occupants was decreased by one. Acquired data by both ultrasonic and temperature sensors were inputted to the Arduino board in which the fuzzy logic controller was embedded. These data were then converted to fuzzy variables according to Equation 1, Equation 2, Equation 3, 
Equation 4, Equation 5, and Equation 6. The Tsukamoto fuzzy inference systems computed the output based on the rule table as shown in Table 1. In the defuzzification stage, the fuzzy output was turned back to the corresponding crisp output, i.e. temperature setpoint, by using weighted average formula. The corresponding infrared signal was transmitted to the air conditioner receiver to regulate the indoor temperature.

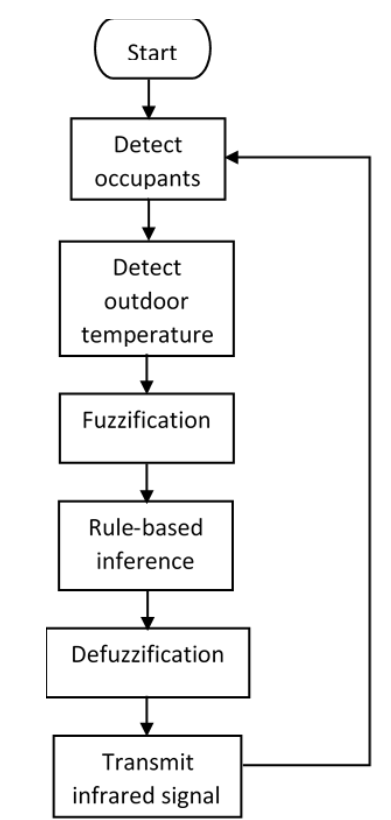

Figure 8. Algorithm Flowchart

The specifications of the air conditioner are listed in Table 2. This specification implies that the air conditioners used in this study do not possess the capability to vary the compressor speed.

\begin{tabular}{cc}
\multicolumn{2}{c}{ Table 2. Specification of Air Conditioners } \\
\hline Type & Daikin STC50NV \\
\hline BTU & 17,100 \\
Power & 1,524 W (2 pk) \\
Type & Standard (Non-inverter) \\
Electricity & 1 phase / $220 \mathrm{~V} / 50 \mathrm{~Hz}$ \\
\hline
\end{tabular}

The thermal comfort perceived by each person was compiled through questionnaires. It was conducted at 11:00 am $-12: 00$ am by 32 students during a class activity. Table 3.

The questionnaire used Likert scale ranging from 1 to 5 . The empirical indicators for each question are shown in

Table 3. Variables, Empirical Indicators, and Questions

\begin{tabular}{|c|c|c|}
\hline Variable & Empirical Indicator & Question \\
\hline $\begin{array}{l}\text { Thermal } \\
\text { comfort }\end{array}$ & $\begin{array}{c}\text { The thermal comfort is measured } \\
\text { based on occupants' perception on } \\
\text { the indoor temperature }\end{array}$ & $\begin{array}{l}\text {-Occupants feel too cold } \\
\text { - Occupants feel too hot } \\
\text { - The indoor temperature support } \\
\text { the class activity }\end{array}$ \\
\hline $\begin{array}{l}\text { User- } \\
\text { friendliness }\end{array}$ & $\begin{array}{c}\text { The user-friendliness is measured } \\
\text { based on occupants' level of } \\
\text { involvement }\end{array}$ & $\begin{array}{l}\text { - Occupants involved in } \\
\text { temperature setting process } \\
\text { - Occupants feel difficult to } \\
\text { initialize and terminate }\end{array}$ \\
\hline
\end{tabular}

\section{Results and Discussion}

\subsection{Design Requirements}

The first experiment was conducted in the morning from 8:00 am until 10:45 am, as shown in Table 4. The cooling mechanism was tested in a $10 \mathrm{~m} \times 6 \mathrm{~m}$ room considering the sensed outdoor temperature and gradually-increasing occupants. From Figure 9, it can be inferred that temperature setpoint is inversely proportional to both outdoor 
Kinetik: Game Technology, Information System, Computer Network, Computing, Electronics, and Control temperature and room occupants. The range of outdoor temperature was not broad enough due to the cloudy weather at the time this study was carried out.

Table 4. Experiment Data in the Morning

\begin{tabular}{cccc}
\hline Time & Outdoor Temp. $\left({ }^{\circ} \mathrm{C}\right)$ & Occupants & Setpoint $\left({ }^{\circ} \mathrm{C}\right)$ \\
\hline $8: 00$ & 23.9 & 0 & 27 \\
$8: 15$ & 24 & 5 & 27 \\
$8: 30$ & 24.2 & 10 & 25 \\
$8: 45$ & 24.1 & 15 & 24 \\
$9: 00$ & 24.4 & 20 & 23 \\
$9: 15$ & 24.5 & 25 & 22 \\
$9: 30$ & 24.6 & 30 & 21 \\
$9: 45$ & 24.7 & 35 & 21 \\
$10: 00$ & 25.1 & 40 & 21 \\
$10: 15$ & 25 & 45 & 21 \\
$10: 30$ & 25.3 & 50 & 20 \\
$10: 45$ & 25.5 & 50 & 20 \\
\hline
\end{tabular}

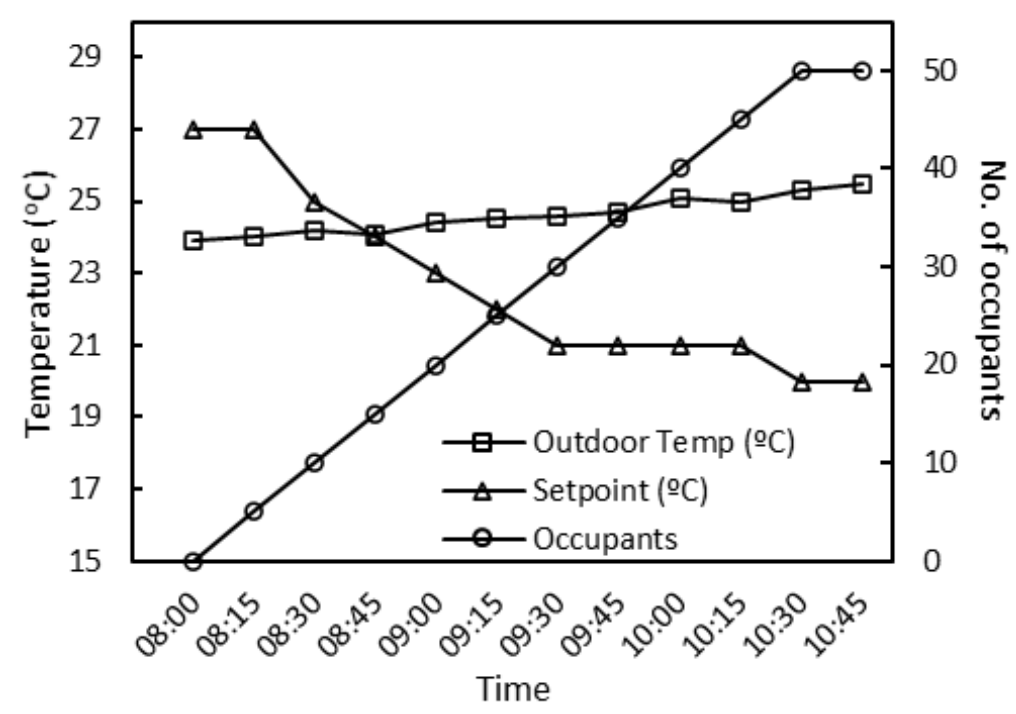

Figure 9. Graph of the Acquired Data in the Morning

The second experiment was carried out in the daytime from 12:00 pm until 14:30 pm, as shown in Table 5.

Table 5. Experiment Data in the Afternoon

\begin{tabular}{cccc}
\hline Time & Outdoor Temp. $\left({ }^{\circ} \mathrm{C}\right)$ & Occupants & Setpoint $\left({ }^{\circ} \mathrm{C}\right)$ \\
\hline $12: 00$ & 30.3 & 5 & 23 \\
$12: 15$ & 30.4 & 10 & 23 \\
$12: 30$ & 30.6 & 15 & 22 \\
$12: 45$ & 30.7 & 20 & 22 \\
$13: 00$ & 30.8 & 25 & 21 \\
$13: 15$ & 31 & 30 & 21 \\
$13: 30$ & 31.1 & 35 & 20 \\
$13: 45$ & 31.2 & 40 & 20 \\
$14: 00$ & 30.9 & 45 & 20 \\
$14: 15$ & 30.7 & 50 & 19 \\
$14: 30$ & 30.8 & 50 & 19 \\
\hline
\end{tabular}

Figure 10 exhibited the same trend line as Figure 9, i.e. the temperature setpoint is inversely proportional to both outdoor temperature and room occupants. The outdoor temperature reached its peak at 13:45 pm, and the temperature setpoint was $20 \mathrm{OC}$ with 40 persons occupying the room. 


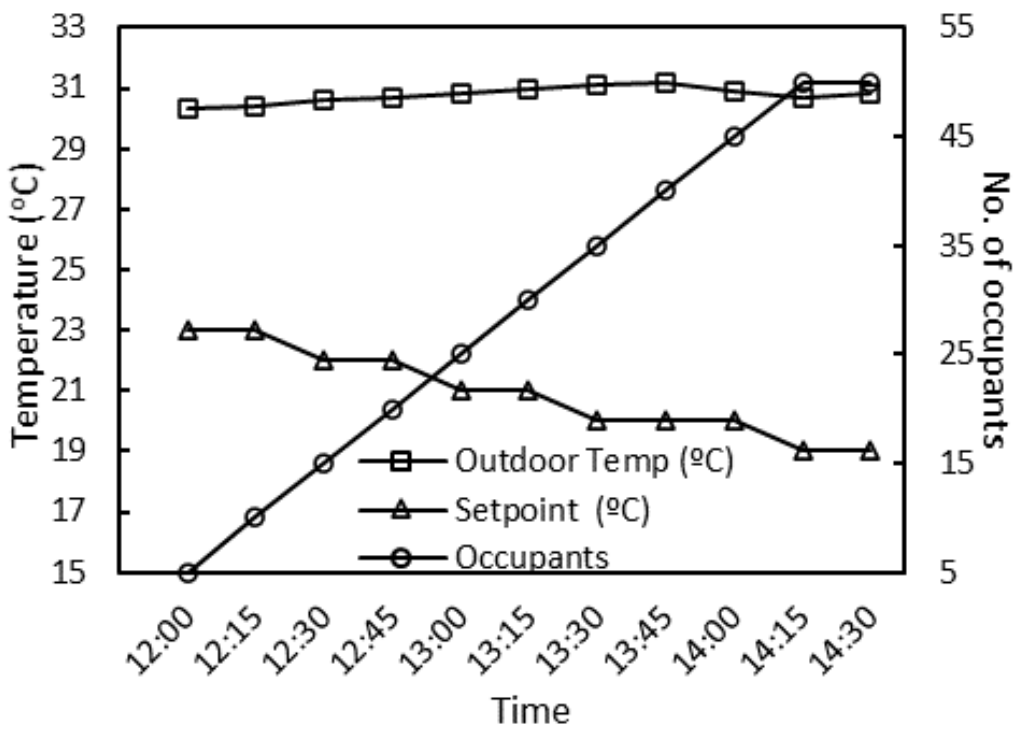

Figure 10. Graph of the Acquired Data in the Afternoon

\subsection{Perceived Thermal Comfort Assessment}

The thermal assessment was conducted at 11:00 am - 12:00 am as depicted in Figure 11. The resulting data are shown in Table 6.

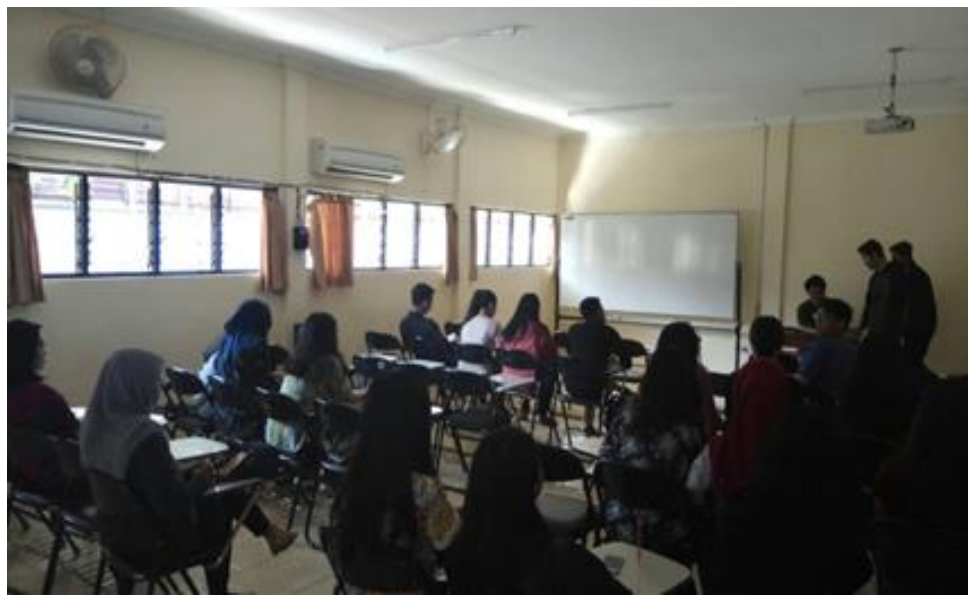

Figure 11. Location of Thermal Assessment

Table 6. Data Obtained During the Perceived Thermal Comfort Test

\begin{tabular}{cccc}
\hline Time & Outdoor Temp. $\left({ }^{\circ} \mathrm{C}\right)$ & Occupants & Setpoint $\left({ }^{\circ} \mathrm{C}\right)$ \\
\hline $11: 00$ & 28.6 & 32 & 21 \\
$11: 05$ & 28.5 & 32 & 21 \\
$11: 10$ & 28.6 & 32 & 21 \\
$11: 15$ & 28.7 & 32 & 21 \\
$11: 20$ & 28.8 & 32 & 21 \\
$11: 25$ & 29 & 32 & 21 \\
$11: 30$ & 29.1 & 32 & 20 \\
$11: 35$ & 29 & 32 & 20 \\
$11: 40$ & 29.2 & 32 & 20 \\
$11: 45$ & 29.4 & 32 & 20 \\
$11: 50$ & 29.5 & 32 & 20 \\
$11: 55$ & 29.7 & 32 & 20 \\
$12: 00$ & 29.9 & 32 & 20 \\
\hline
\end{tabular}



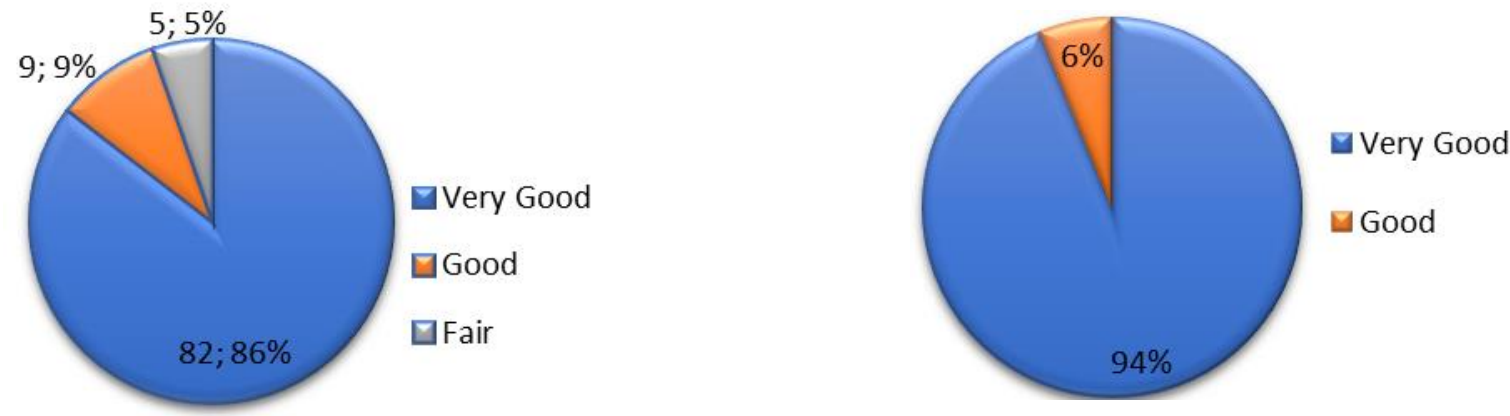

Figure 12. Questionnaire Result for Thermal Comfort (Left) and User-Friendliness (Right)

The obtained data from the questionnaire were then translated to five categories, i.e. Very Good, Good, Fair, Bad, and Very Bad, for each variables. The result is shown in Figure 12. The result of the questionnaire regarding the thermal comfort implied that there were 82, 9, and 5 feedbacks associated with the category of Very Good, Good, and Fair, respectively. Meanwhile, the results regarding user-friendliness showed that there were 60 and 4 feedbacks associated with a category of Very Good and Good, respectively. The validity of each question was confirmed using validity test with siginificance level of $5 \%$ which yields $r_{\text {table }}=0.301$.

\subsection{Compressor Output}

To investigate the energy consumption, the operating cycles of the air conditioner were recorded.

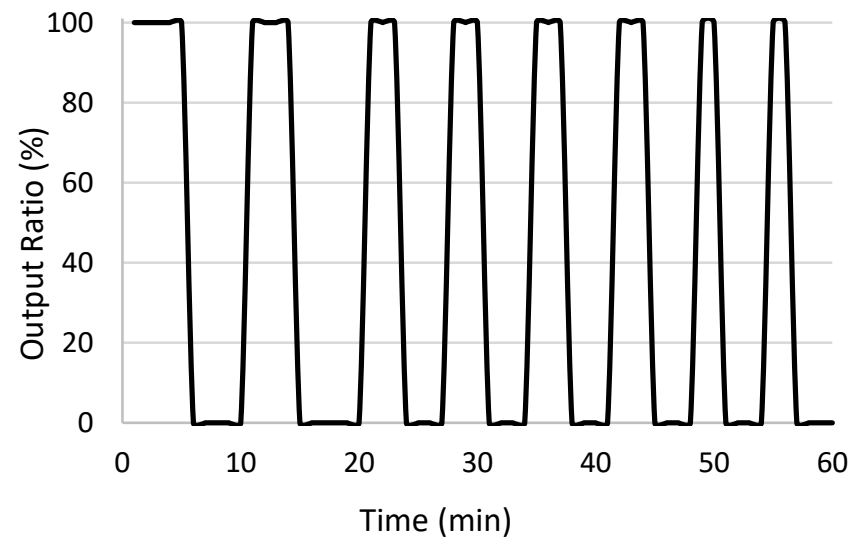

Figure 13. The Compressor Output Percentage

Since the air conditioner was controlled in a fixed frequency fashion, then the compressor output percentages related to a full load were $0 \%$ and $100 \%$, as shown in Figure 13. It means that the output ratio of $0 \%$ occurs when the compressor stops while the output ratio of $100 \%$ occurs when the compressor runs. The observation was done during the daytime for an hour. The recording was terminated after one hour because the cycle repetition was approximately the same afterward. As the time passed, the ON periods were getting shorter because the room temperature were already at the vicinity of setpoint, and thus might lead to higher energy efficiency.

\section{Conclusion}

An automated approach to set the temperature has been carried out by using an Arduino-controlled device. It does not require human intervention during the operating process. The Tsukamoto fuzzy inference was employed to convert the outdoor temperature and the number of occupants to the air conditioner setpoint. The thermal comfort perceived by occupants was satisfactory despite surrounding variations. The air conditioner compressor output also exhibited the right profile to be considered as energy-efficient. In future works, the thermal comfort can be assessed in comparison to that of a convertible frequency air conditioner.

\section{References}

[1] L. Pérez-Lombard, J. Ortiz, and C. Pout, "A review on buildings energy consumption information," Energy Build., vol. 40, no. 3, pp. 394-398, 2008. https://doi.org/10.1016/j.enbuild.2007.03.007

[2] A. Arteconi, A. Mugnini, and F. Polonara, "Energy flexible buildings: A methodology for rating the flexibility performance of buildings with electric heating and cooling systems," Appl. Energy, vol. 251, no. May, p. 113387, 2019. https://doi.org/10.1016/j.apenergy.2019.113387 
[3] P. H. Shaikh, N. B. M. Nor, P. Nallagownden, I. Elamvazuthi, and T. Ibrahim, "A review on optimized control systems for building energy and comfort management of smart sustainable buildings," Renew. Sustain. Energy Rev., vol. 34, pp. 409-429, 2014. https://doi.org/10.1016/j.apenergy.2019.113387

[4] A. Elmoudi, O. Asad, M. Erol-Kantarci, and H. T. Mouftah, "Energy Consumption Control of an Air Conditioner Using Web Services," Smart Grid Renew. Energy, vol. 02, no. 03, pp. 255-260, 2011. http://dx.doi.org/10.4236/sgre.2011.23028

[5] M. Mowad, A. Fathy, and A. Hafez, "Smart home automated control system using android application and microcontroller," Int. J. Sci. Eng. Res., vol. 5, no. 5, pp. 935-939, 2014.

[6] G. Graditi et al., "Innovative control logics for a rational utilization of electric loads and air-conditioning systems in a residential building," Energy Build., vol. 102, pp. 1-17, 2015. https://doi.org/10.1016/j.enbuild.2015.05.027

[7] W. W. Shein, Y. Tan, and A. O. Lim, "PID controller for temperature control with multiple actuators in cyber-physical home system," in Proceedings of the 2012 15th International Conference on Network-Based Information Systems, NBIS 2012, 2012, pp. 423-428. https://doi.org/10.1109/NBiS.2012.118

[8] C. C. Cheng and D. Lee, "Smart sensors enable smart air conditioning control," Sensors, vol. 14, no. 6, pp. 11179-11203, 2014 https://doi.org/10.3390/s 140611179

[9] H. Khayyam, "Adaptive intelligent control of vehicle air conditioning system," Appl. Therm. Eng., vol. 51, no. 1-2, pp. 1154-1161, 2013. https://doi.org/10.1016/j.applthermaleng.2012.10.028

[10] Husein, M. Budiman, and M. Djamal, "Duty cycle control on compressor of split air conditioners using internet of things embedded in fuzzy-PID," Int. J. Electr. Eng. Informatics, vol. 11, no. 1, pp. 112-124, 2019. https://doi.org/10.15676/ijeei.2019.11.1.7

[11] S. K. Dash and G. Mohanty, "Intelligent Air Conditioning System using Fuzzy Logic," Int. J. Sci. Eng. Res., vol. 3, no. 12, pp. 1-6, 2012.

[12] Y. Hong, J. Lin, C. Wu, and C. Chuang, "Multi-Objective Air-Conditioning Control Considering Fuzzy Parameters Using Immune Clonal Selection Programming," IEEE Trans. Smart Grid, vol. 3, no. 4, pp. 1603-1610, 2012. https://doi.org/10.1109/TSG.2012.2210059

[13] T. Fukazawa, Y. Iwata, J. Morikawa, and C. Ninagawa, "Stabilization of neural network by combination with AR model in FastADR control of building air-conditioner facilities," IEEJ Trans. Electr. Electron. Eng., vol. 11, no. 1, pp. 124-125, 2016. https://doi.org/10.1002/tee.22196

[14] N. Yamtraipat, J. Khedari, J. Hirunlabh, and J. Kunchornrat, "Assessment of Thailand indoor set-point impact on energy consumption and environment," Energy Policy, vol. 34, no. 7, pp. 765-770, 2006. https://doi.org/10.1016/j.enpol.2004.07.009

[15] T. Hoyt, E. Arens, and H. Zhang, "Extending air temperature setpoints: Simulated energy savings and design considerations for new and retrofit buildings," Build. Environ., vol. 88, pp. 89-96, 2015. https://doi.org/10.1016/j.buildenv.2014.09.010

[16] S. N. N. Ekasiwi, N. H. Abdul Majid, S. Hokoi, D. Oka, N. Takagi, and T. Uno, "Field survey of air conditioner temperature settings in hot, humid climates, part 1: Questionnaire results on use of air conditioners in houses during sleep," J. Asian Archit. Build. Eng., vol. 12, no. 1, pp. 141148, 2013. https://doi.org/10.3130/jaabe.12.141

[17] N. H. A. Majid, N. Takagi, S. Hokoi, S. N. N. Ekasiwi, and T. Uno, "Field survey of air conditioner temperature settings in a hot, dry climate (Oman)," HVAC R Res., vol. 20, no. 7, pp. 751-759, 2014. https://doi.org/10.1080/10789669.2014.953845

[18] H. B. Gunay, W. Shen, G. Newsham, and A. Ashouri, "Modelling and analysis of unsolicited temperature setpoint change requests in office buildings," Build. Environ., vol. 133, pp. 203-212, 2018. https://doi.org/10.1016/j.buildenv.2018.02.025

[19] T. A. Nguyen and M. Aiello, "Energy intelligent buildings based on user activity: A survey," Energy Build., vol. 56, pp. 244-257, 2013. https://doi.org/10.1016/j.enbuild.2012.09.005

[20] H. Hagras, I. Packham, Y. Vanderstockt, N. McNulty, A. Vadher, and F. Doctor, "An intelligent agent based approach for energy management in commercial buildings," in IEEE International Conference on Fuzzy Systems, 2008, pp. 156-162. https://doi.org/10.1109/FUZZY.2008.4630359

[21] G. S. Song, J. H. Lim, and T. K. Ahn, "Air conditioner operation behaviour based on students' skin temperature in a classroom," Appl. Ergon., vol. 43, no. 1, pp. 211-216, 2012. https://doi.org/10.1016/j.apergo.2011.05.009

[22] J. Yao, "Modelling and simulating occupant behaviour on air conditioning in residential buildings," Energy Build., vol. 175, pp. 1-10, 2018. https://doi.org/10.1016/j.enbuild.2018.07.013

[23] J. Kim, Y. Zhou, S. Schiavon, P. Raftery, and G. Brager, "Personal comfort models: Predicting individuals' thermal preference using occupant heating and cooling behavior and machine learning," Build. Environ., vol. 129, pp. 96-106, 2018. https://doi.org/10.1016/j.buildenv.2017.12.011

[24] Z. Gou, S. Y. S. Lau, and P. Lin, "Understanding domestic air-conditioning use behaviours: Disciplined body and frugal life," Habitat Int., vol. 60, pp. 50-57, 2017. https://doi.org/10.1016/j.habitatint.2016.12.009

[25] A. Silva, N. Mendes, R. Vilain, M. Pereira, and K. C. Mendonça, "On the development of a thermal comfort control for classrooms conditioned by split-type systems," in ASME International Mechanical Engineering Congress and Exposition, Proceedings (IMECE), 2019, vol. 8, no. May, pp. 2-7, 2020. https://doi.org/10.1115/IMECE2019-11426

[26] "https://www.accuweather.com/en/id/salatiga/202819/june-weather/202819?year=2019," 2019. 